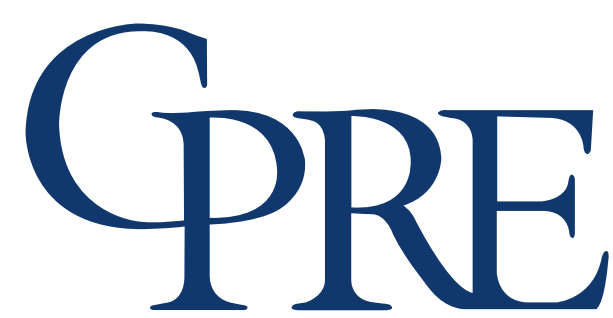

CONSORTIUM FOR POLICY RESEARCH IN EDUCATION

How State

Education Agencies

Acquire and

Use Research

in School

\section{Improvement Strategies}

By Margaret E. Goertz, Carol Barnes and Diane Massell

Over the last two decades, state and federal laws and grant programs, such as state accountability polices, the No Child Left Behind Act (NCLB), Race to the Top, Title I School Improvement Grants, and State Longitudinal Data System Grants, have given state education agencies (SEAs) considerably more responsibilities for directing and guiding the improvement of low-performing schools. At the same time, they have pressed SEAs and school districts to incorporate research-based school improvement policies and practices in their statewide systems of support for low-performing schools, technical assistance for districts, professional development for teachers, and school improvement programs. Policymakers have urged SEAs to engage with organizations external to their own agencies to extend their strained capacity, and to help them collect and use research or other evidence (see, for example, Rennie Center, 2004). A variety of organizations involved in this enterprise have emerged over the last two decades (Rowan, 2002). For example, the 2002 authorization of the Elementary and Secondary Education Act's (ESEA) comprehensive assistance centers was specifically designed to provide and encourage SEA's use of research.

Although studies of districts' and schools' use of research exist (see for example, Coburn, Honig, \& Stein, 2009; Daly \& Finnigan, 2011; Farley-Ripple, 2012), we know little about how SEAs search for, select, and use research and other kinds of evidence in their school improvement strategies. While one might assume similarities in research use behaviors, both the organizational structures of SEAs and the population of external organizations with which they interact are quite different than schools and districts, and the most recent in-depth study of SEAs was conducted nearly 20 years ago (Lusi, 1997). The exploratory study on which this brief is based was designed to fill that gap by examining: 1) where SEA staff search for research, evidence-based, and practitioner knowledge related to school improvement; 2) whether and how SEA staff use research and these other types of knowledge to design, implement, and refine state school improvement policies, programs and practices; and, 3) how SEAs are organized to manage and use such knowledge (Goertz, Barnes, Massell, Fink, \& Francis, 2013).

To clarify the nature of evidence that SEAs sought and used, we distinguished among three types of knowledge in our data collection and analysis. We define researchbased knowledge as research findings that have
Stanford University

University of Michigan

University of

Wisconsin-Madison

Northwestern University
This Policy Brief was derived from the research report, State Education Agencies' Acquisition and Use of Research Knowledge in School Improvement Strategies. Visit www.cpre.org/SEA to download a free copy. 
been to varying degrees "collated, summarized, and synthesized," and then are presented in ways that provide empirical or theoretical insights or make them otherwise informative (Davies \& Nutley, 2008). We include in this category published original research, research syntheses, summaries or metaanalyses, and evaluation reports. We also consider forms of research-based knowledge that are designed for use in practice; that is, models, programs, protocols or other tools that embed research or research-based practices in guides to action. Older knowledge utilization models assumed that simply transmitting such knowledge to policymakers or practitioners would be sufficient to create change. But new models show that research-based knowledge is not sufficient to meet the needs of professionals using it. Integrating contextual, local, and practitioner knowledge with research knowledge is critical to developing "useable" knowledge to guide action (Honig \& Coburn, 2008; Hood, 2002; Huberman, 1990; Lindblom \& Cohen, 1979; Weiss, MurphyGraham, Petrosino, \& Gandhi, 2008). Therefore, we considered how the SEAs incorporated other evidencebased knowledge, which we define as data, facts, and other information relevant to the problem of school improvement, such as formative feedback loops on implementation, and practitioner knowledge, which is the information, beliefs, and understanding of context that practitioners acquire through experience, along with research in their decision-making processes.

The formal organizational structure of most SEAs has long been criticized for its hierarchical and segmented nature, and for its focus on compliance instead of on guidance and support for meaningful improvements in schools or districts. In her research study of two SEAs, Lusi (1997) argued that flatter, less segmented management structures could help build internal and external connections and produce the kind of

The research reported here was supported by a grant from the William T. Grant Foundation. This brief has been internally and externally reviewed to meet CPRE's quality assurance standards. The opinions expressed are those of the authors and do not necessarily reflect the views of the William T. Grant Foundation, CPRE, or its institutional partners. adaptive organization that would be more conducive to coherent improvement policies and the flow of knowledge. More recent studies in other settings confirm that flexible professional connections across traditional organizational boundaries improve problem-solving using varied but relevant expertise (Dutton \& Heaphy, 2003; Weick \& Sutcliffe, 2001; Wenger, McDermott, \& Snyder, 2002). Sociologists have long studied these kinds of connections, known as "social networks," to understand the diffusion of knowledge and innovation within and across organizations, including more recent studies of schools and districts (Daly, 2010). A few researchers have used social network theory and methods to study state education policy networks (Miskel \& Song, 2004; Song \& Miskel, 2005). We applied social network perspectives and methods here to examine SEA's communication structures, search and incorporation networks, and network properties, such as social capital, and to identify the most central "knowledge brokers" or influential knowledge sources in the research and other knowledge networks.

Our study included three SEAs that are located in different regions of the country and vary in size (from 250 to 500 staff), organizational structure, and school improvement strategies. Data for the study were collected between 2010 and 2012. We conducted indepth interviews with high-level SEA staff involved directly in school improvement and in related programs (e.g., curriculum and instruction, accountability, special programs, teacher policy) and with a small number of leaders of external organizations that were central to research use in the SEAs. We also sent a web-based survey to all professional staff in the two smaller SEAs, and to all staff working in school improvement and related departments and a representative sample of other professional staff in the third SEA. Our analyses are based on a total of 62 interviews and 300 surveys in the three SEAs ${ }^{1}$, as well as documents describing SEA school improvement policies and tools designed for district and school use.

Respondents identifed the offices, organizations and individuals they turned to both within and outside their SEA when communicating about work, and

1 All survey respondents were asked whether their work related "in any way to improving low-performing schools and school districts" in their state. We used results from all respondents who answered "yes" to this question; that is, staff who self-identified as being involved in school improvement work regardless of the SEA office in which they worked. 
more specifically, when seeking research, data, and practitioner advice on programs and practices targeted at improving low-performing schools and school districts. ${ }^{2}$ We used the survey data to identify internal and external sources of research and other types of knowledge, to analyze the size, strength, and configuration of the four networks, including patterns of cross-office or within-office communication, and to identify the most highly connected knowledge brokers and influential individuals, offices, or organizations in the networks. We drew on the direct, interpersonal networks of these influential individuals along with interview data to corroborate and interpret the broader network analyses, and to provide more specific information on the internal and external sources of research or other knowledge. Interview data and document reviews also provided more detail on the types and qualities of research or other forms of knowledge that SEA staff sought and used in school improvement decision-making, the research incorporation process, and institutional, political, or other factors that influenced research search, incorporation, and use.

The findings presented in this brief focus on how SEAs acquired and used research knowledge in their school improvement policies and programs. We did not examine the effects of their use of research or other evidence on improving school or student outcomes. Because we focused on research use for school improvement in a small number of states, our findings may not generalize to other SEAs or other education policy areas. Our study, however, is the first to systematically map information networks within SEAs and between SEA staff and external sources of support, and provides important insights into how SEA staff search for and incorporate research in their work.

\section{The Structure and Strength of SEA Research Networks}

Multiple SEA staff in the three study states actively searched for and were receptive to research ideas and related information from both within and outside their agencies. About 75\% of the staff in each agency asked their SEA colleagues for research advice, while a little less than one-third turned to external organizations or individuals for similar information. In each SEA, some, but not all, of these staff named multiple colleagues, offices and external organizations as sources of research information.

Contrary to the usual image of SEAs as "siloed" organizations, our network analyses showed considerably more cross-office connections than we anticipated given the literature on SEA structures.

Respondents attributed cross-department communications to multiple factors, including state and federal accountability demands, competition for federal grants that required integrated proposals, reduced SEA staffing, and SEA leaders committed to more collaborative organizational cultures. For example, special education staff in State C perceived that NCLB accountability requirements had brought them into school improvement meetings in an unprecedented way. Other federal initiatives, such as the Race to the Top grants, stimulated cross-office search and exchange of research-based ideas in State B. Leadership in all three SEAs also facilitated crossagency collaboration by creating cross-office teams to share information or work on common tasks or problems. States B and C were active participants in an Academy of Pacesetting States hosted by the Center on Innovation and Improvement (CII), a national comprehensive assistance center that convened cross-office state teams on a regular basis to share and discuss research or other topics related to statewide systems of school improvement. State A established cross-departmental task forces to design its system of tiered-intervention and to manage and monitor performance on the SEA's major goals.

These broad, more informal cross-department and external connections facilitated the flow of research information and new ideas, but internal crossdepartment connections were weaker than those within departments. This suggests that colleagues within the same department or office engaged in more frequent interactions, and these had a greater impact on individuals' work than did the cross- 
department connections. Thus, formal organizational structures still delineate many functional responsibilities and lines of communication. While the school improvement research networks in each state included an array of staff from across the SEAs and numerous external organizations, only a small number of individuals, offices and external partners were central actors in these networks. We identified the key actors or offices by mapping each participant's location in the networks (e.g., central or more peripheral), as well as the strength ${ }^{3}$ and direction ${ }^{4}$ of their connections to each other. Influential and well-connected individuals and offices tended to be clustered more centrally in the core of the network maps. "Influential" participants are those who were highly sought after for research information; that is, they were mentioned as a source of advice by many SEA staff. "Well-connected" participants are those who both sought research ideas and information from a range of sources, and, at the same time, provided information to a range of SEA colleagues, thus serving as knowledge brokers in the research networks. These two sets of individuals or offices tended to overlap considerably. Figures 1-3 below show the structure of the three SEA research networks, and the staff, offices and external organizations involved in, and their location within, each network.

The directors of school improvement were the most influential and well-connected SEA staff in the research networks in States B and C (Figures 1 and 2 ). These directors and some of their staff (green nodes) were connected with several other salient offices related to school improvement. In State B, these key participants included leadership from the Assessment and Accountability Department (grey nodes), including staff in the Research and Evaluation Unit (red nodes), the Commissioner's and Deputy Commissioner's Offices related to academic matters (yellow nodes), ESEA program monitoring (aqua nodes), and a consultant from special education (pink node). We also found strong connections between the Curriculum and Instruction Office (dark green nodes) and the School Improvement Office, both of which were within the School Improvement Department. Two external organizations - a statewide professional membership association and the state's regional comprehensive assistance center (black shapes)were centrally located and had stronger connections to the School Improvement Department than most other organizations in State B's research network, although the CII and a state university were also quite influential.

School improvement and curriculum and instruction are housed in different departments in State C, and primarily leadership from both departments, along with very few staff, were at the center of its research network. While the Assessment Offices were not as prominent as they were in State $B$, directors of a very small Research Office housed in the Commissioner's Office and ESEA program monitoring were highly influential in the network. Thus, like State B, most of the influential internal brokers were in formally designated leadership roles. Also like State B, a few external organizations were prominent in the research network - the CII, State C's regional comprehensive assistance center, and a statewide professional membership association.

In contrast to the other states, the Research Department was the most influential in State A (Figure 3). It resided at the center of State A's research network, with multiple connections to most other departments in its SEA. This relatively large office plays multiple roles in its SEA: conducting research reviews for offices throughout the agency; helping program offices design, procure, and manage program evaluations; preparing data reports and briefings for accountability review teams; and, developing analytical tools. Some of this work is done in-house, and some, particularly

3 Strength of network connections was measured though a combination of the reported frequency of communication about research or other kinds of information, and the influence respondents perceived the resulting information to have on their work. Degree of strength was considered using a matrix ranging from a cell defined by highly influential/daily contact (200) to a cell defined by not influential/a few times per year contact (0.5).

4 An individual or office can be the seeker of research information (considered an "out-tie") or the named source of research information (considered an "in-tie"). To examine ties between SEA members and external members of networks, we used "out-ties" from our SEA respondents forming in-ties to external organizations as we interviewed a subsample, but did not survey, external organizations.

5 We also identified the most central staff or offices using rank ordered standardized centrality measures showing the percentage of all possible ties directed into sources of research (in-ties) as well as out from those seeking information (out ties). 
program evaluations and literature reviews, is contracted out. But the most well-connected research knowledge broker was the Accountability

Department that conducts formal reviews and monitors the performance of low-performing school districts. The School Improvement Department and its offices, along with the Curriculum and

Instruction Department, were also highly influential hubs of activity. Similar to State C, curriculum and instruction and school improvement are housed in separate departments, but though influential, the Curriculum and Instruction Department did not have many direct research connections with school improvement in State A. Finally, perhaps due to the role of the Research Office, external organizations remained at the periphery of State A's research network.

Figure 1

State B, Research Network, Strength of Ties

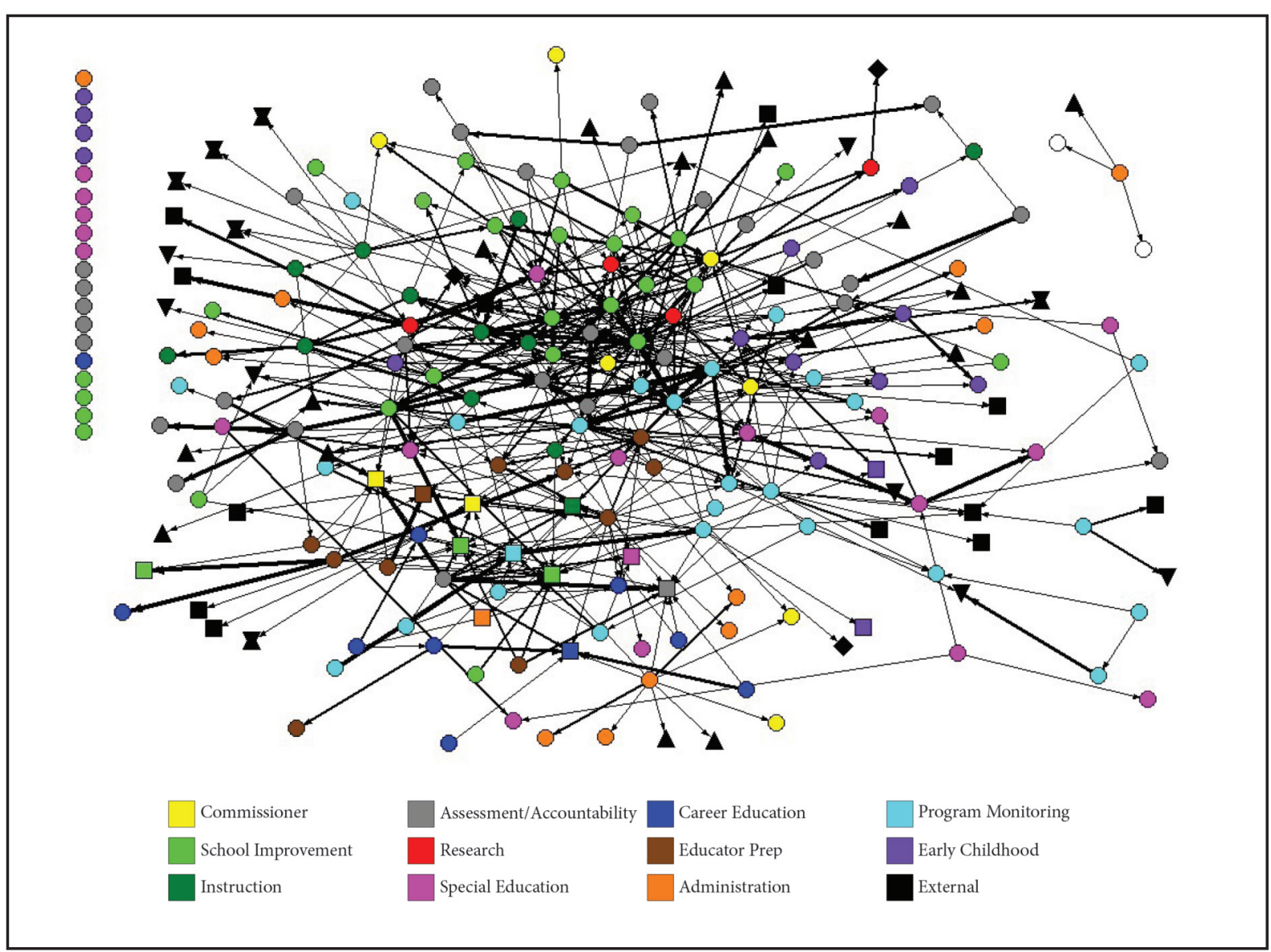




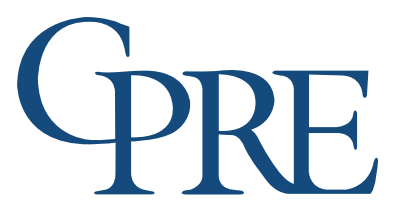

Figure 2

State C, Research Network, Strength of Ties

8<smiles>[CH]C</smiles><smiles>CO</smiles>
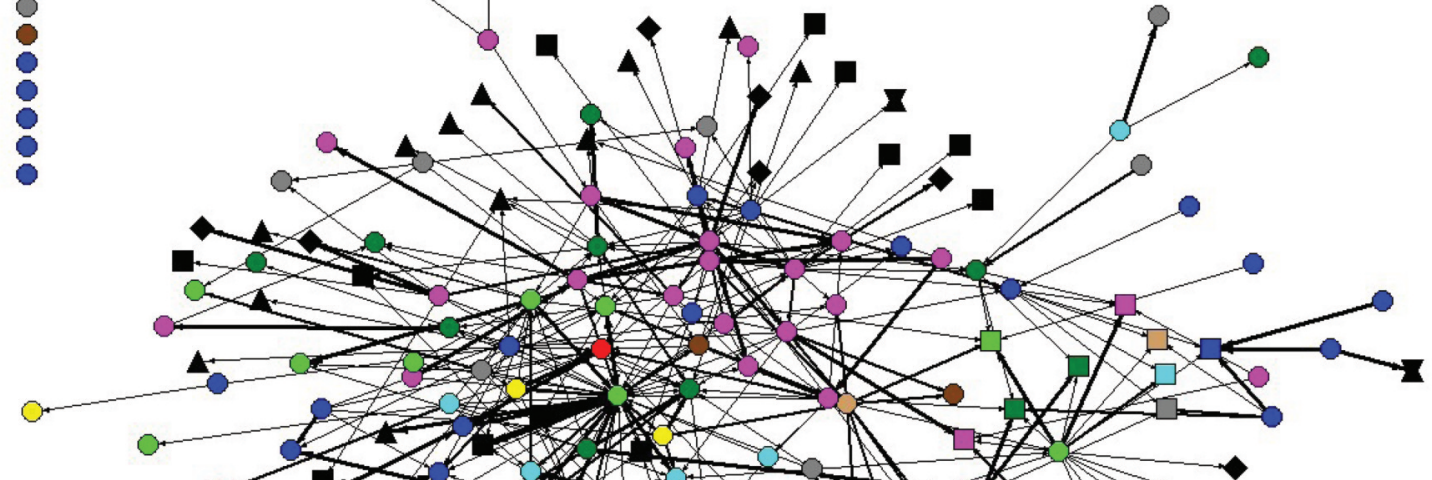

$$
\text { o- }
$$
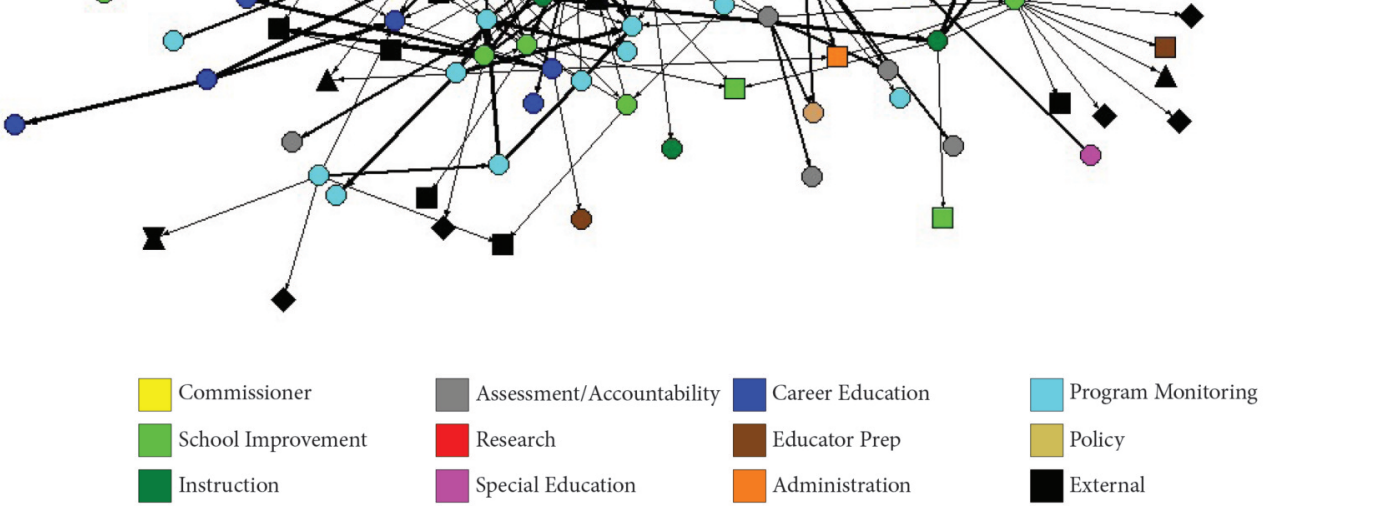

Assessment/Accountability
Research
Special Education


Figure 3

State A, Research Network, Strength of Ties

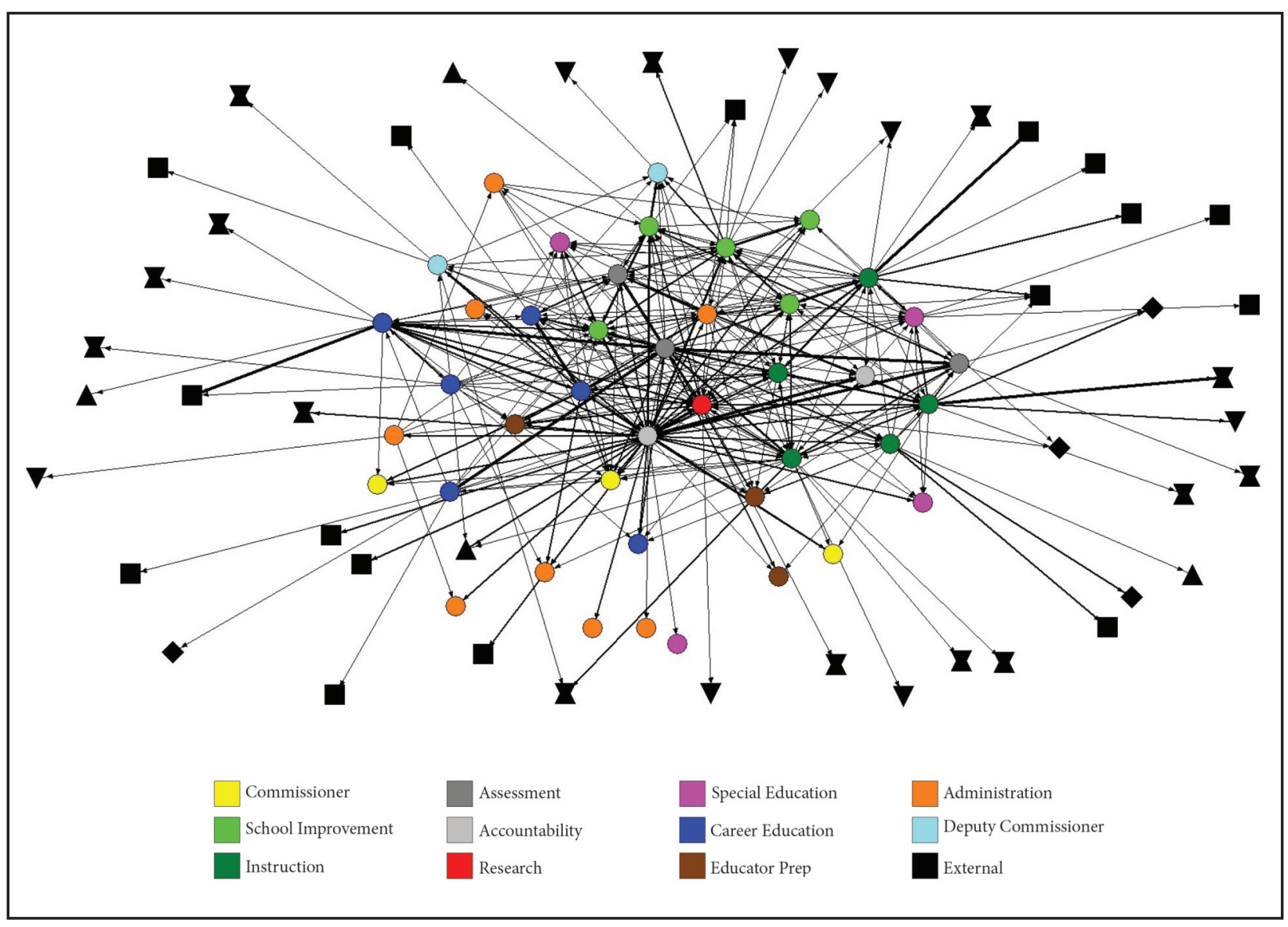


External Sources for Research Knowledge

Although fewer SEA actors turned to external sources of research on school improvement, these organizations played a key role in the research that policymakers accessed and used. The SEA staff named a large and diverse array of external organizations-between 37 in State A and 42 in State B. These organizations were invited to present new ideas about school improvement, provided or collaboratively developed research-based tools and strategies, conducted evaluations, synthesized research on relevant topics, and more. As we discussed above, a subset of these external organizations played central roles in SEA research networks in States B and C.

The most commonly mentioned source of external research information was the federal government. (See Figure 4.) SEA staff turned to federal agencies, including several offices within the U.S. Department of Education, and federally funded centers, such as the ESEA comprehensive assistance centers, regional education labs, and other technical assistance centers that support the implementation of more targeted educational programs (e.g., special education or vocational education). The second largest external source of research advice was professional membership associations. These included: 1) associations focused on specific subject matter, or teaching and learning more generally, such as state and national reading, mathematics and technology organizations, and the ASCD; 2) occupationally focused associations, such as the Council of Chief State School Officers or state-level associations representing superintendents, principals, and federal program administrators; and, 3) regional organizations, such as the Southern Regional Education Board. Staff in the three SEAs, however, reached out primarily to national, not state, professional membership associations for research advice. Fewer SEA staff sought research from institutions of higher education or research organizations, although one to two universities did play an integral role in school improvement designs and delivery in States B and C, and SEA staff in State A often turned to university faculty for help on specific projects. SEA staff also turned to a different mix of federal organizations across the three states. For example, State A sought research advice more frequently from various regional education labs than staff in States B and C who relied more heavily on the regional and content centers within the comprehensive assistance center network.

Figure 4

External Sources for Research Knowledge

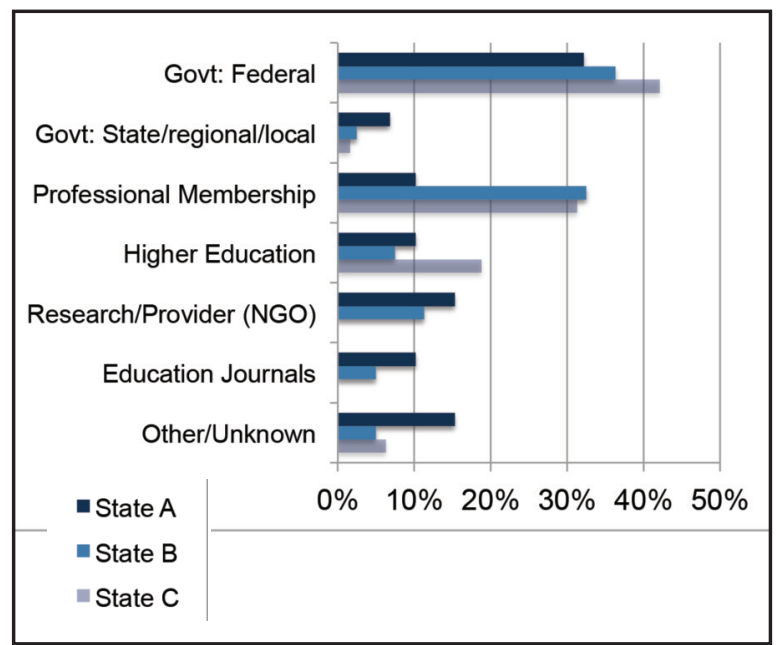

This variation in the states' external research networks reflected differences in stages of policy development, internal capacity, the structure of external environments, and prior partnership histories. For example, the basic components of the State A's school improvement system had been in place for many years; the overarching design was not a target for major review. As a result, State A was more likely to pull in a range of external partners, on an as-needed basis, to co-develop very discrete and specific tools and resources. This process was facilitated by the SEA's robust research office. State $\mathrm{C}$, in contrast, was bracing for more and more schools to come within its purview for not meeting state or federal accountability standards in the midst of a very spare and declining SEA workforce. With limited research capacity and expertise in school improvement, SEA staff turned to the CII, as well as their own regional comprehensive assistance center and a state professional membership association, to help them redesign their supports and create a research-based infrastructure of tools to monitor and assist schools. Their engagement with these organizations was frequent and extended over many years. Similarly, having very limited capacity for 
high school improvement and guidance, States B and C sought assistance from the National High School Center. State C, for example, used this Center's research and the work of a consulting group to develop an "early warning system" to identify students at risk of dropping out of school.

Much of the external search was driven by personal connections and prior work histories. While a few of the SEA staff who we interviewed suggested they used a range of Internet and academic resources, many turned to their existing network of academics and/or memberships and affiliations with education organizations to access research and new ideas. SEA staff also turned to organizations with which the SEA had a history of doing work. For example, regional area education agencies and their respective membership association have long partnered with the SEA in State B in delivering services to schools. These regional government agencies pioneered strategies for improvement that State B later adopted as part of its statewide systems of support, such as a design for working with low-performing schools to model an improvement process. State C, which did not have an equivalent set of regional government partners, turned instead to a state-level professional membership association with which they had long worked in school improvement design and delivery. Organizations that have a previous work history with SEAs are attractive sources of research-based knowledge because they often know the local context in which the SEA is working, are familiar with the strengths of SEA staff, and are viewed as credible sources of information.

Some external sources of research were also viewed as more neutral purveyors of knowledge than the SEA, an asset if targeted schools were wary of the state reform agenda. Similarly, the expertise carried by external organizations or individuals could provide an outsiders' perspective on whether state efforts were within the bounds of best practice - an important metric for state agencies and policymakers who are engaged in often uncertain work. For example, when State A undertook a review of its district and school improvement standards, it asked its regional education lab to identify the research underlying the proposed standards and their impact on schools. The SEA then compiled this research into a guide and posted it on its website so that, as one staff person noted, "people understand they're being held accountable to things that research tells us are important. But also so that...we can tie the assistance around some of what research is telling us." State C sought out the advice and engagement of a university faculty member who had been a well-respected former superintendent, recognizing that his support would open the doors, and the minds, of other superintendents.

Finally, external organizations frequently played an important role in synthesizing and packaging research to make it useable, and useful, to SEA work. Many of the SEA staff we interviewed expressed a desire to know more about research, but it was difficult for them to find time to stay current with the literature and to incorporate research directly into their school improvement work. An administrator in State A explained, "Because our work [in my office] is so huge, I've relied on consultants and organizations that can capture and summarize... research so that we can figure out, focus on how we're going to use it to inform our work." As we describe in the following sections, the more influential external organizations in SEAs' networks brokered, jointly developed with states, or helped states adapt research-based, but useable tools that translated research into more specified guides for action.

\section{Incorporating Research Within Core Networks}

While broad, but relatively weaker cross-department and external research networks facilitated the search process and the flow of diverse ideas in the SEAs, a set of well-connected, influential SEA staff brought research and other kinds of information from these different sources into stronger, smaller working groups that collectively addressed problems of school improvement. We conceptualized these groups as "core networks." ${ }^{\circ}$ These groups, which generally included leaders and other staff within school improvement offices, a few key external organizations and, in a very few cases, colleagues from other departments in the agency, enabled key SEA staff, who were typically central in the practitioner as well as research networks, to actually

6 Here we draw on work of Wenger, McDermott, and Snyder (2002) who studied "communities of practice" in other settings. 
incorporate research into strategies that were workable in the context of their respective states.

As research has shown in other settings (see, for example, Barnes, Camburn, Sanders, \& Sebastian, 2010; Honig \& Coburn, 2008; Spillane, Reiser, \& Reimer, 2002), SEA staff incorporated research into their school improvement strategies through a distinctly social process in which the network members interpreted, challenged, and otherwise made sense of research over time. During this incorporation process, the core network groups used local practitioners' feedback, state professionals' experience, and external partners' knowledge of relevant research to contextualize various research findings in light of their states' school improvement needs. In contrast to models of research dissemination in which generalized, primarily decontextualized findings advanced by researchers are transmitted to users, in these core networks, users and a few providers worked collectively to adapt research to address particular problems and, in some cases, to co-construct new useable knowledge for guiding action.

One characteristic of the core networks was that a group of people came together to address common problems and goals. Key school improvement staff in States B and C who had developed strong ties to key liaisons in the federal comprehensive assistance center system were able to learn about relevant research and how to apply it from developers of school improvement models or promising practices rooted in that research, and with states who were puzzling over similar problems to their own. Not only could the SEA staff in these states receive research tailored to particular school improvement policy needs they faced, but they could then see how it might be put into action from other SEAs who were early implementers.

Members of the core networks also worked together over time to develop, refine and use a set of ideas, protocol, tools, and frameworks. In these instances, the research-based blueprints or models were adapted through core groups for use in the context of a particular state. State C, for example, turned to the CII's Handbook on Restructuring and Substantial School Improvement (Walberg, 2007) when redesigning its school improvement plans. The handbook contains a consolidated checklist of indicators for schools, districts and teachers to use to identify areas for improvement, a research-based guide to action that they found readily usable, and useful. The SEA, however, took a proactive stance with CII to help them transform these materials into what SEA staff considered a more focused and useful format. Working with their own school improvement coaches (who are retired educators), CII staff, and their regional comprehensive assistance center, State C created a more streamlined set of indicators, cutting the number from the Handbook by half.

As this example suggests, the core networks included strong ties to networks of practitioners "on the ground" and in professional associations, as well as the research networks. Practitioner networks provided feedback on how improvement strategies were working in the field, what needed clarifying, or what could be changed. A core group member in State B described how they used meetings with a group of regional school district school improvement staff as a sounding board for their strategies: "because they're in the schools doing school improvement with the local districts. And a lot of times we can say, 'Okay, here's what we're thinking....Is that too much? Is it not enough?'” Staff in State B turned to professional membership organizations as well for practitioner input.

Professional membership organizations were central to State C's practitioner network, as were the comprehensive assistance centers. In contrast, the SEA in State A sought much of its practitioner advice from its districts and district networks.

SEA staff also perceived information, decisionmaking, evolving improvement strategies and ideas to be more trustworthy and efficacious within the context of these core networks and collective work. For example, when asked if the people in his core work network have the expertise to find, and then use evidence to successfully improve lowperforming schools, an office director reported:

There is no one individual that holds all the information, which is why we have a group... all of those different people hold enough pieces that we can have conversations and share information across the table that can ... push us along to that ideal goal at the end. 
Resources such as "communal memory" created a collective sense of efficacy and supported core network members such that no one person had to know everything. When asked if and why she trusted research and other school improvement information exchanged within a core network, one influential office director in State B said: "Because we digest it together. And people challenge each other." She continued with an example of a similar process: "We solve problems. What are we going to do about this?... And people bring in research and we'll table things and [then] come back to them with the research, and then we'll challenge the research." An influential leader in State C noted: "I want to validate what [researchers are] saying. When you have those strong networks, you build upon that professional knowledge and practice."

\section{Research Use}

The SEAs in our study valued and used research to inform the design of their school improvement frameworks, processes, tools, and other forms of school improvement assistance. As our earlier examples show, however, SEA staff gravitated to research that they perceived as relevant to their context, actionable, feasible, and helpful in addressing pressing problems of policy and practice, sometimes called "research designed for use." In addition to searching for this kind of specific and contextrelevant research, they also generated it by coupling research with practitioner knowledge.

The states confronted similar problems and challenges in their work, even though many features of their systems of supports for lowperforming schools varied. For instance, at different points in time all three searched for research to create school improvement frameworks and/or planning processes that would be more effective in leveraging school or district change. All three sought research to help districts be more successful in managing the problems of their lowperforming schools. And each used research to develop tools and processes that would aid the growing number of schools coming under the purview of accountability mandates.

While foundational documents, such as the school improvement frameworks, could contain extensive references to the literature-State B's framework contained 92 different citations, for example-SEA staff most often relied on research syntheses or research-based tools or strategies to provide very specific and concrete guides to action. For instance, State C drew on this type of research to overhaul their district and school improvement planning processes. The SEA viewed the plans submitted by low-performing sites as lacking a coherent theory of action, and premised on very localized notions of good practice rather than solid research. When they heard a presentation about the CII's Handbook, they seized upon it to solve these problems. As described in the preceding section, the SEA created a more streamlined set of indicators that they believed would be more doable for sites. They also encouraged the CII to create a web-based platform using the indicators to help them more efficiently and cost-effectively monitor progress and interact with local educators. Building on this positive experience, the CII and the regional comprehensive assistance center continued to be a major source of research used by State $\mathrm{C}$ to develop new tools and processes, such as "change maps," a process that the state could use to differentiate their technical assistance to sites. It was developed by the regional center and built on research from Banathy (1996), among others.

State A brought together research with their own knowledge and local experience to develop a wide array of web-based school improvement tools and supports for its school and districts. The SEA collaborated with its urban school district network to identify common problems and develop guides for addressing these problems. They created a Professional Learning Community Guidance Document in conjunction with the National Institute for School Leadership (NISL) and a professional working group from districts and schools. The document, which provides guidelines for developing and strengthening instructional teams at the school level, includes references to researchbased curriculum units from NISL and related research and SEA resources for each stage of the process. Similarly, the SEA's school improvement, data, technology, and curriculum and instruction offices worked with a national consulting firm and five urban school districts to create a District Data Team Toolkit. Drawing on a research-based data- 
driven inquiry and action cycle, the toolkit provides detailed modules and rubrics to help districts engage in inquiry and use data to inform districtlevel decisions.

The states similarly pulled in research or evidence that had rich, descriptive details of practice that they could pass on to schools or delivery providers. One SEA staff member in State B noted that John Hattie's book, Visible Learning: A Synthesis of Over 800 Meta-Analyses Relating to Achievement (Hattie, 2009), had "taken off like wildfire" with their school coaches, in part because it presents a research-based dashboard for comparing innovations, a tool these providers could use to help their schools evaluate needs and select effective practices. SEA staff in both States A and B used the research-based Instructional Rounds in Education (City, Elmore, Fiarman, \& Teitel, 2009) to focus their own and their districts' school improvement strategies more specifically on classroom observations of instruction, student learning and academic content. State B was also trying to actively involve practitioners in recommending research-based resources. Educators could submit instructional resources aligned to the teaching and learning strand of the state's framework on its website. But they had to also submit their assessment of the scholarship underlying the proposed resource, such as a judgment about the quality of evidence, how "seminal" the research was, and whether it was confirmed by other studies or experts. The state includes a link to this research evidence next to the recommended practice. Such attention underscores how deeply the reference to research has been embedded in the norms of SEAs.

States also created their own original research by undertaking both formal and informal evaluations of their school improvement policies and programs. The extent to which the three SEAs conducted formal evaluations varied, however, depending on resources and internal capacity to select and guide external evaluations. SEA staff sometimes designed and conducted evaluations on their own, and other times they contracted with external partners. Under the direction of its Research Office, State A was the most involved in undertaking formal evaluations. State B contracted with national research organizations to evaluate their statewide system of support and their Title I School Improvement Grant program. In contrast, State $\mathrm{C}$ was more likely to use measures of academic improvement in identified schools and informal educator feedback to assess program success. But all of the SEAs drew on external evaluations of instructional programs or practices to create lists of acceptable or recommended programs or vendors to assist schools and districts.

\section{Summary and Implications}

In summary, SEA staff in our three study states actively sought and were receptive to research. Contrary to a uni-dimensional model of knowledge utilization, where research users are viewed as passive recipients of published research, research use was a multi-dimensional process in our sites. Multiple SEA staff reached out to multiple internal and external sources of research. Incorporating research into policy and practice was often a social process, where SEA staff worked with each other, practitioners, and external partners to make sense of research and adapt it to their local context. And key brokers of research inside and outside the SEAs facilitated the research search and incorporation process. Decision-makers were more likely to seek and use research designed for use than published academic studies to guide their actions. They also understood that research, particularly from recognizable and trusted sources, lent credibility to their efforts and motivated practitioners.

Although the findings reported here come from an exploratory study of only three SEAs in one policy area, they shed light on ways that SEAs and policymakers can strengthen research-based knowledge use in their organizations.

1. SEAs should draw on the infrastructure outside their boundaries, such as technical assistance centers, state and national professional membership organizations, other professional networks, and universities, to access research and research designed for use. This action will, however, require SEAs to develop a culture of research use, and build the capacity to broker research search and incorporation, and to assess the underlying quality of the research and research designed for use produced by these 
organizations. By cultivating multiple knowledge brokers within the SEA to access and circulate a diverse array of research, SEA knowledge networks will have access to a broader range of expertise and could also be less vulnerable to staff turnover.

2. SEAs should also nurture, identify, and connect knowledge brokers in their agencies and in external organizations who work on common problems. SEA staff could develop and lead ongoing networks involving research organizations, practitioners, and their own staff to solve specific problems and advance state policy. The New York State Education Department's Education Finance Research Consortium provides one example of this approach. Fostering working groups composed of influential SEA brokers, key research sources and practitioners to adapt generalized findings into more useable information in the context of particular state problems can facilitate the incorporation of research into policy and practice.

3. Policymakers should encourage and support SEA evaluations of their own programs. These evaluations, particularly of the implementation of school improvement programs, provide critical feedback to agency staff. But SEAs often lack the human resources to design these studies and the fiscal resources to conduct them.

Our study also raised more questions than we could answer, given the limited scope of our inquiry. First, researchers should study the use of research and other types of evidence in additional SEAs and other education policy areas to see whether the findings reported here generalize to other SEA contexts. Second, research should examine connections among patterns of internal or external information flow within an SEA, the number and type of information sources, the types of evidence people access and use in decision-making, and consequences for policy and practice. Third, there is a need to assess the quality of research acquired by SEA staff and underlying research designed for use products. While many of the products identified in our study were written by or cited national experts, sometimes research was added in a fairly superficial manner. Finally, there is a major need to strengthen the knowledge base, which includes supporting more varied types of research on policy implementation and effects in understudied areas of education policy. 
Barnes, C., Camburn, E., Sanders, B., \& Sebastian, J. (2010). Developing instructional leaders: Using mixed methods to explore the black box of planned change in principals' professional practice. Educational Administration Quarterly, 46(2), 241-279.

Banathy, B. H. (1996). Designing social systems in a changing world. NY: Plenum Press.

City, E. A., Elmore, R. F., Fiarman, S. E., \& Teitel, L. (2009). Instructional rounds in education: A network approach to improving teaching and learning. Cambridge, MA: Harvard Education Press.

Coburn, C. E., Honig, M. I., \& Stein, M. K. (2009). What's the evidence on district's use of evidence? In J. Bransford, D. J. Stipek, N. J.Vye, L. Gomez, and D. Lam (Eds.), Educational improvement: What makes it happen and why? (pp. 67-86). Cambridge: Harvard Education Press.

Daly, A. J., (Ed.) (2010). Social network theory and educational change. Cambridge, MA: Harvard Education Press.

Daly, A. J, \& Finnigan, K. S. (2011). The ebb and flow of social network ties between district leaders under high-stakes accountability. American Educational Research Journal, 48(1), 39-79.

Davies, H. T. O., \& Nutley, S. M. (September 2008). Learning more about how research-based knowledge gets used: Guidance in the development of new empirical research. New York, NY: William T. Grant Foundation.

Dutton, J., \& Heaphy, E. (2003). Coming to life: The power of high quality connections at work. In K. Cameron, J. Dutton, \& R. Quinn (Eds.), Positive organizational scholarship (pp. 263-278). Thousand Oaks, CA: Berrett-Koehler.

Goertz, M. E., Barnes, C., Massell, D., Fink, R. E., \& Francis, A (2013). State education agencies' acquisition and use of research knowledge in school improvement strategies. Philadelphia, PA: Consortium for Policy Research in Education.

Farley-Ripple. E. N. (2012). Research use in central office decisionmaking: A case study. Education Management, Administration and Leadership, 40(6), 786-806.

Hattie, J. (2009).Visible learning: A synthesis of over 800 metaanalyses relating to achievement. London \& New York: Routledge, Taylor\& Francis Group.

Honig, M., \& Coburn, C. (2008). Evidence-based decision making in school district central offices: Toward a policy and research agenda. Educational Policy, 22(4), 578-608.

Hood, P. (2002). Perspectives on knowledge utilization in education. West Ed.

Huberman, M. (1990). Linkages between researchers and practitioners: A qualitative study. American Educational Research Journal, 27(2), 363-391.

Lindblom, C. E., \& Cohen, D. K. (1979). Usable knowledge. New Haven, CT:Yale University Press.

Lusi, S. F. (1997). The role of state departments of education in complex school reform. New York:Teachers College Press.
Miskel, C. G., \& Song, M. (2004). Passing Reading First: Prominence and processes in an elite policy network. Educational Evaluation and Policy Analysis, 26(2), 89-109.

Rennie Center for Education Research \& Policy (2004). Examining state intervention capacity: How can the state better support low performing schools $\&$ districts? Boston, MA: The Rennie Center for Education Research \& Policy.

Rowan, B. (2002). The ecology of school improvement: Notes on the school improvement industry in the United States. Journal of Educational Change, 3(3-4), 283-314.

Song, M., \& Miskel, C. G. (2005). Who are the influentials? A crossstate social network analysis of the reading policy domain. Educational Administration Quarterly, 41(1), 7-44.

Spillane, J., Reiser, B. J., \& Reimer, T. (2002). Policy implementation and cognition: Reframing and refocusing implementation research. Review of Educational Research, 72(3), 387-431.

Walberg, H. (Ed.) (2007). Handbook on restructuring and substantial school improvement. Greenwich, CT: Information Age Publishing.

Weick, K. E., \& Sutcliffe, K. M. (2001). Managing the unexpected: Assuring high performance in an age of complexity. San Francisco, CA: Jossey-Bass.

Weiss, C. H., Murphy-Graham, E., Petrosino, A., \& Gandhi, A. G. (2008). The fairy godmother and her warts: Making the dream of evidence-based policy come true. American Journal of Evaluation, 29(1), 29-47

Wenger, E., McDermott, R., \& Snyder, W. M. (2002). Cultivating communities of practice: A guide to managing knowledge. Boston, MA: Harvard Business School Press. 


\section{About the Authors:}

Carol A. Barnes is a senior researcher at the Consortium for Policy Research in Education (CPRE) at the University of Michigan. Her research includes the macro and micro influences on school improvement in high-poverty settings, especially the relationship between policy, research and instructional or leadership practice. Barnes' research on planned improvement range from close examinations of teachers and principals incorporating research or policy principles into their practice, to evaluations of federal or state policies aimed at school improvement. She is currently studying how state education agencies are organized to manage and use evidence in their policies or practices to improve low-performing schools.

Margaret E. Goertz is a professor emerita of education and a senior researcher at CPRE in the University of Pennsylvania's Graduate School of Education. She specializes in the study of education finance and governance policy, and has conducted research on state and local implementation of Title I and the No Child Left Behind Act; the design and implementation of standards-based reform by states, school districts, and schools; federal and state accountability policies; and state and local district resource allocation. She is currently studying how state education agencies search for and use research in their school improvement strategies.

Diane Massell is a senior researcher at CPRE at the University of Michigan. Her research focuses on $\mathrm{K}-12$ education policy, particularly in the design and implementation of standards-based reform, federal supports for state education agencies, and policies and programs for school and district improvement. In addition to this research on how state education agencies are using research and other evidence in school improvement policies, she is reviewing state practices using federal School Improvement Grant resources to turn around low-performing schools, and consulting with a state education agency on reviewing and revising its statewide system of support. 


\section{Policy Brief}

CONSORTIUM FOR POLICY RESEARCH IN EDUCATION

Non Profit

U.S. Postage

PAID

Permit No. 2563

Philadelphia, PA

\section{About the Consortium for Policy Research in Education (CPRE)}

Established in 1985, CPRE unites researchers from seven of the nation's leading research institutions in efforts to improve elementary and secondary education through practical research on policy, finance, school reform, and school governance. CPRE studies alternative approaches to education reform to determine how state and local policies can promote student learning. The Consortium's member institutions are the University of Pennsylvania, Teachers College-Columbia University, Harvard University, Stanford University, the University of Michigan, University of Wisconsin-Madison, and Northwestern University.

The University of Pennsylvania values diversity and seeks talented students, faculty, and staff from diverse backgrounds. The University of Pennsylvania does not discriminate on the basis of race, sex, sexual orientation, religion, color, national, or ethnic origin, age, disability, or status as a Vietnam Era Veteran or disabled veteran in the administration of educational policies, programs or activities; admissions policies, scholarships or loan awards; athletic, or University administered programs or employment.

Questions or complaints regarding this policy should be directed to Executive Director, Office of Affirmative Action, 1133 Blockley Hall, Philadelphia, PA 19104-6021 or (215) 898-6993 (Voice) or (215) 898-7803 (TDD).

\section{CPRE.ORG}

